\title{
Desensitization of the adrenocorticotrophin responses to arginine vasopressin and corticotrophin-releasing hormone in ovine anterior pituitary cells
}

\author{
A Hassan, S Chacko and D Mason \\ Department of Zoology, University of Canterbury, Christchurch, New Zealand \\ (A Hassan is currently at Georgetown University Medical Center, 4000 Reservoir Road, Room 377 Building D, Washington DC 20007, USA) \\ (Requests for offprints should be addressed to D Mason, Department of Zoology, University of Canterbury, Private Bag 4800, Christchurch, New Zealand; \\ Email: drusilla.mason@canterbury.ac.nz)
}

\begin{abstract}
Following repeated or prolonged exposure to either corticotrophin-releasing hormone $(\mathrm{CRH})$ or arginine vasopressin (AVP), pituitary adrenocorticotrophin (ACTH) responsiveness is reduced. This study compared the characteristics of desensitization to CRH and AVP in perifused ovine anterior pituitary cells. Desensitization to AVP occurred at relatively low AVP concentrations and was both rapid and readily reversible. Treatment for 25 min with AVP at concentrations greater than $2 \mathrm{nM}$ caused significant reductions in the response to a subsequent $5 \mathrm{~min} 100 \mathrm{nM}$ AVP pulse $\left(\mathrm{IC}_{50}=6.54 \mathrm{nM}\right)$. Significant desensitization was observed following pretreatment with $5 \mathrm{nM}$ AVP for as briefly as $5 \mathrm{~min}$. Desensitization was greater following a 10 min pretreatment, but longer exposures caused no further increase. Resensitization was complete within $40 \mathrm{~min}$ following $15 \mathrm{~min}$ treatment with $10 \mathrm{nM}$ AVP. Continuous perifusion with 0.01 nM CRH had no effect on AVP-induced
\end{abstract}

desensitization. Treatment with $0 \cdot 1 \mathrm{nM} \mathrm{CRH}$ for either 25 or $50 \mathrm{~min}$ caused no reduction in the response to a subsequent $5 \mathrm{~min}$ stimulation with $10 \mathrm{nM}$ CRH. When the pretreatment concentration was increased to $1 \mathrm{nM}$ significant desensitization was observed, with a greater reduction in response occurring after $50 \mathrm{~min}$ treatment. Recovery of responsiveness was progressive following $50 \mathrm{~min}$ treatment with $1 \mathrm{nM} \mathrm{CRH}$ and was complete after $100 \mathrm{~min}$. Our data show that in the sheep AVP desensitization can occur at concentrations and durations of AVP exposure within the endogenous ranges. This suggests that desensitization may play a key role in regulating $\mathrm{ACTH}$ secretion in vivo. If, as has been suggested, CRH acts to set corticotroph gain while AVP is the main dynamic regulator, any change in responsiveness to CRH may significantly influence the overall control of ACTH secretion.

Journal of Endocrinology (2003) 178, 491-501

\section{Introduction}

Regulation of adrenocorticotrophin (ACTH) secretion during stress is a multi-factorial process, with the hypothalamic neuropeptides corticotrophin-releasing hormone $(\mathrm{CRH})$ and arginine vasopressin (AVP) being the most physiologically important ACTH secretagogues (Antoni 1993). Both hormones are secreted into the hypophyseal portal circulation in a pulsatile fashion (Engler et al. 1989, Antoni 1993) and stimulate ACTH secretion from pituitary corticotrophs via activation of distinct $G$ proteincoupled receptors (De Keyzer et al. 1994). The relative importance of $\mathrm{CRH}$ and AVP in the physiological regulation of ACTH secretion remains a matter of debate. The ability of the two hormones to stimulate ACTH secretion appears to vary depending on the species. In both the rat (Vale et al. 1983) and horse (Evans et al. 1993) CRH is a much more potent secretagogue than AVP, whereas in the sheep some groups, but not all, have reported that AVP is the more potent secretagogue (Familari et al. 1989, Evans et al. 1993, McFarlane et al. 1995). In all cases a marked synergism between CRH and AVP has been observed (Antoni 1986). It has been proposed that this synergism may allow $\mathrm{CRH}$ to function as a permissive signal, setting the overall responsiveness of the corticotroph, while AVP is the main dynamic hypothalamic ACTH-releasing factor (Antoni 1993, Evans et al. 1996). Studies in the rat have shown an increase in the expression of AVP in parvocellular neurons during stress and good correlation in general between changes in the number of AVP receptors and ACTH responsiveness (Aguilera 1994). This suggests that AVP is an important modulator of ACTH responsiveness during stress.

In vivo studies have shown that the ACTH responses to both AVP and CRH undergo regulatory changes during chronic stress (Aguilera 1994). Additionally, prolonged 
infusion of either CRH (Wynn et al. 1988) or AVP (Antoni et al. 1985, Koch \& Lutz-Bucher 1985) results in down-regulation of their respective receptors. In vitro studies have shown that prior exposure to either AVP or $\mathrm{CRH}$ can result in a reduction in $\mathrm{ACTH}$ response, or desensitization, to a subsequent stimulation with the same neuropeptide (Reisine \& Hoffman 1983, Holmes et al. 1984, Hoffman et al. 1985, Evans et al. 1988, 1993, 1996, Thomson et al. 1990, Castro 1993). The treatments used in these in vitro studies to induce desensitization were either of high concentration, long duration or a combination of both and did not closely match the characteristics of endogenous $\mathrm{CRH}$ and AVP pulses. The following examples illustrate this. Treatment of rat anterior pituitary segments with $100 \mathrm{nM}$ AVP for $4 \mathrm{~h}$ greatly reduced their responsiveness to a subsequent stimulation with either $10 \mathrm{nM}$ or $1 \mu \mathrm{M}$ AVP (Holmes et al. 1984). Similarly a $1 \mathrm{~h}$ treatment with $100 \mathrm{nM}$ CRH caused substantial desensitization to a subsequent stimulation with $100 \mathrm{nM}$ CRH (Reisine \& Hoffman 1983). In perifused sheep anterior pituitary cells repeated stimulation with 10 min AVP pulses (100 or $2000 \mathrm{nM}$ ) every $60 \mathrm{~min}$ for $4 \mathrm{~h}$ reduced the ACTH responsiveness of the cells, and successive $10 \mathrm{~min}$ pulses of $\mathrm{CRH}$ $(0 \cdot 2-2000 \mathrm{nM})$ also caused decreased ACTH release with time (Evans et al. 1988).

In contrast to these in vitro treatments, endogenous $\mathrm{CRH}$ and AVP pulses are brief and of relatively low maximal concentration. In vivo studies have provided information on the pituitary portal characteristics of pulses of CRH and AVP under basal and stressed conditions in sheep (Caraty et al. 1988, 1990, Engler et al. 1989, Battaglia et al. 1998). Basal secretion rates were very low for both AVP and CRH (e.g. ranging between 5 and $83 \mathrm{pM}$ for AVP and between 1 and $19 \mathrm{pM}$ for CRH) (Caraty et al. 1988). Exposure to a stressor resulted in pulses of secretion of AVP and CRH which usually lasted less than $\sim 30 \mathrm{~min}$. The maximal AVP concentration in portal plasma following exposure to a stressor ranged from $\sim 1 \mathrm{nM}$ for acute haemorrhage (Caraty et al. 1988) to $\sim 6 \mathrm{nM}$ for high-dose insulin-induced hypoglycaemia (2 $\mathrm{IU} / \mathrm{kg}$ ) (Caraty et al. 1990). For CRH the maximal portal plasma concentrations were between $\sim 0.2 \mathrm{nM}$ for acute haemorrhage (Caraty et al. 1988) and $\sim 0.4 \mathrm{nM}$ for insulin-induced hypoglycaemia (2 IU/kg) (Caraty et al. 1990) (our conversion of all data). Therefore it is very unlikely that corticotrophs would be exposed to CRH or AVP at either the levels or for the lengths of time that have been used, in general, to induce desensitization in vitro. As a result the question remains as to whether desensitization seen under experimental conditions plays a role in the physiological regulation of ACTH secretion, or reflects pharmacological actions of the regulators.

The main aim of the current study was to determine whether desensitization occurs in vitro in ovine anterior pituitary cells in response to CRH and AVP treatments which more closely match the concentrations and durations of $\mathrm{CRH}$ and AVP pulses observed in the hypophyseal circulation of the sheep. By investigating desensitization under these more physiologically relevant conditions we were able to make a better assessment of the role of these processes in the regulation of ACTH secretion. Secondly, in view of the hypothesis that CRH acts as a permissive signal setting the overall responsiveness of the corticotroph we assessed the effect of treatment with $\mathrm{CRH}$ on the ability of AVP to induce desensitization to a subsequent stimulation. Finally, we wanted to establish the relationship between the degree of desensitization and pulse duration and magnitude, and to determine the time required for resensitization to occur, since these properties may give some clues as to the mechanisms involved in the regulation of the receptor.

\section{Materials and Methods}

\section{Cell preparation}

Pituitary glands were collected from a local abattoir in accordance with animal ethics laws of New Zealand and the guidelines of the University of Canterbury. Dispersed ovine anterior pituitary cells were prepared as previously described (Evans et al. 1985, Le Beau \& Mason 1994). Briefly, whole pituitary glands were removed from sheep shortly after slaughter and placed into cold, sterile Hepes buffer $(25 \mathrm{mM}$ Hepes, $137 \mathrm{mM} \mathrm{NaCl}, 5 \mathrm{mM} \mathrm{KCl}$, $10 \mathrm{mM}$ glucose and $0 \cdot 002 \%$ phenol red, $\mathrm{pH} 7 \cdot 3$ ) containing antibiotic and antimycotic agents (100 $\mathrm{U}$ penicillin/ $\mathrm{ml}, 100 \mathrm{mg}$ streptomycin/ml and $0 \cdot 25 \mathrm{mg}$ amphotericin $\mathrm{B} / \mathrm{ml})$. A suspension of dispersed cells from the combined anterior lobes of seven pituitaries was obtained following a combination of enzymatic (collagenase type II, $480 \mathrm{U} / \mathrm{ml}$ Hepes buffer; Sigma Chemical Co., St Louis, MO, USA) and mechanical disruption. The dispersed cells were washed by centrifugation $\left(300 \mathrm{~g}\right.$ for $5 \mathrm{~min}$ at $4{ }^{\circ} \mathrm{C}$ ) and resuspension in Hepes buffer, and after the final wash were resuspended in culture medium (Dulbecco's modified Eagle's medium (DMEM); Sigma) containing $3.7 \mathrm{mg}$ $\mathrm{NaHCO}_{3} / \mathrm{ml}, 584 \mathrm{mg}$ L-glutamine/ml, non-essential amino acids, antibiotic/antimycotic agents (as above) and $25 \mathrm{mM}$ Hepes at $\mathrm{pH} 7 \cdot 3$, and supplemented with $10 \%$ new-born calf serum (NCS) (Gibco Laboratories, Life Technologies, Inc., Grand Island, NY, USA). For perifusion experiments $4.5 \times 10^{6}$ cells were plated into nonadherent plastic Petri dishes (Labserv, Auckland, New Zealand) in $20 \mathrm{ml}$ DMEM+NCS. For static culture experiments the cells were plated into 24-well multidishes (NUNC A/S, Roskilde, Denmark) at a density of $0.5 \times 10^{6}$ live cells $/ \mathrm{ml}$ per well. In both cases cells were incubated for $20 \pm 2 \mathrm{~h}$ at $37^{\circ} \mathrm{C}$ in a water-saturated, $5 \%$ $\mathrm{CO}_{2}: 95 \%$ air atmosphere. 


\section{Multi-column perifusion experiments}

The multi-column perifusion system, as described previously and with modifications (McIntosh \& McIntosh 1983, Evans et al. 1985, 1988, 1996), allows for the simultaneous perifusion of up to 15 cell chambers, or columns. Through the use of a solenoid switching system various trains of peptide hormones and pharmacological agents can be applied to the cells.

Following overnight incubation the cells from each culture plate were recovered by centrifugation and the supernatant was replaced with $170 \mu$ l of a slurry of pre-swollen Sephadex G-25 fine (Sigma) suspended at a ratio of $1: 1.5(\mathrm{v} / \mathrm{v})$ in Krebs-Ringer solution (KR; $125 \mathrm{mM} \mathrm{NaCl}, 4.7 \mathrm{mM} \mathrm{KCl}, 1.2 \mathrm{mM} \mathrm{KH}_{2} \mathrm{PO}_{4}, 2.5 \mathrm{mM}$ $\mathrm{CaCl}_{2}, 1.2 \mathrm{mM} \mathrm{MgSO}_{4}, 3.6 \mathrm{mM} \mathrm{NaHCO} \mathrm{N}_{3}, 25 \mathrm{mM}$ Hepes, $10 \mathrm{mM}$ glucose and antibiotic/antimycotic agents as above). Slurries of $80 \mu \mathrm{l}$ Bio-Gel P2 (Biorad Laboratories, Hercules, CA, USA) suspended 1:1.5 (v/v) in KR) and $80 \mu \mathrm{l}$ Sephadex G-25 fine suspended 1:1.5 (v/v) in KR were added sequentially to the columns to form a bed on which the mixture of cells and Sephadex was placed. Perifusion was commenced at a flow rate of $0.16 \mathrm{ml} / \mathrm{min}$ with the perifusion medium (KR containing $0 \cdot 05 \%$ alkali-treated casein (Livesey \& Donald 1982) and $0 \cdot 005 \%$ ascorbate (Sigma); KR/ATC) and the cells being maintained at $37^{\circ} \mathrm{C}$ by a water jacket surrounding the columns and the media reservoirs. Effluent from the columns was collected in 5 and $10 \mathrm{~min}$ fractions and frozen for subsequent measurement of ACTH concentration by RIA.

During an experiment cells were perifused with a 'basal' solution (i.e. KR/ATC) and a 'test' solution containing either AVP or CRH. The tubing carrying these solutions was connected to the pump tubing by a Y-junction. At any given time one of these lines was clamped closed. Through the use of a solenoid-actuated switching system the perifusion solution could be rapidly and precisely changed between the 'test' and 'basal' solutions. When the cells were perifused with 'basal' KR/ATC plus two separate 'test' solutions, the basal line was manually transferred between KR/ATC and the second 'test' solution.

A variety of different experimental protocols were used in perifusion experiments. While the protocol used depended on the aim of the particular experiment, the design of all experiments shared some common features. These are described below while the details of the specific treatment regimes used in individual experiments can be found in Results. Each of the 15 columns in the perifusion system was randomly assigned an experimental treatment. Typically, each of the different treatments was repeated in at least two independent columns. In all experiments cells were perifused with 'basal' KR/ATC for at least $90 \mathrm{~min}$ at the beginning of the experiment, allowing them to recover from transfer into the columns. During this period ACTH secretion dropped to a consistently low level.
Experimental treatments began at the end of this run-in period.

\section{Static culture experiments}

Following overnight incubation the culture medium was removed from each well and replaced with $1 \mathrm{ml} \mathrm{KR/}$ ATC. After a $60 \mathrm{~min}$ pre-incubation at $37^{\circ} \mathrm{C}$ this buffer was replaced with $1 \mathrm{ml} \mathrm{KR/ATC} \mathrm{containing} \mathrm{CRH}$ at various concentrations. The cells were treated with $\mathrm{CRH}$ for a range of times and then washed once with KR/ATC. One millilitre of KR/ATC, with or without CRH, was then added to each well to start the 90 min test incubation, which was carried out at $37^{\circ} \mathrm{C}$. At the completion of the test incubation, a sample of buffer was removed and frozen for subsequent analysis of ACTH concentration by RIA.

\section{$R I A$}

ACTH RIA was performed as previously described (Evans et al. 1985). The antiserum used (rabbit anti-porcine ACTH) was a gift from Dr Richard Donald, Christchurch Hospital (Christchurch, New Zealand) and the highly purified ovine ACTH, used for ${ }^{125} \mathrm{I}$-radioiodination and assay standards, was a gift from $\mathrm{Dr} \mathrm{C} \mathrm{H} \mathrm{Li}$, Hormone Research Laboratory, University of California (San Francisco, CA, USA). Intra- and inter-assay coefficients of variation were $5 \cdot 71$ and $6 \cdot 14 \%$ for static culture samples and 6.69 and $9 \cdot 46 \%$ for multi-column perifusion samples.

\section{Data and statistical analysis}

In perifusion experiments the ability of a particular treatment to induce desensitization was assessed by measuring its effect on the response to a subsequent $5 \mathrm{~min}$ stimulation with either $100 \mathrm{nM}$ AVP or $10 \mathrm{nM}$ CRH. The magnitude of the response to each of these 'test' pulses was calculated as the total amount of ACTH released in the period following commencement of the pulse $(20 \mathrm{~min}$ for AVP or $30 \mathrm{~min}$ for CRH), minus basal secretion (calculated using the mean value of the hormone concentration in the two or three fractions immediately preceding either the pulse or the pretreatment). Therefore the term 'response' refers to stimulated ACTH secretion. For the purposes of analysis the results from each perifusion column were treated as $n=1$. In general, for each treatment there were two or three replicates (columns) per experiment (one cell preparation) and there were two or three experiments. Data are reported as means \pm S.E.M.

Static culture experiments were repeated three or four times using different cell preparations. Within each experiment triplicate or quadruplicate observations were made for each treatment. The data are reported as means \pm S.E.M. with the $n$ value equal to the number of experiments. Stimulated ACTH secretion was calculated by subtracting the unstimulated $\mathrm{ACTH}$ release (i.e. ACTH release in 
the absence of stimulating agent) from the total ACTH release occurring in the presence of $\mathrm{CRH}$ during the test incubation.

Statistical significance was assessed using either Student's $t$-test or ANOVA as indicated in the text. $P<0 \cdot 05$ was considered significant.

\section{Results}

Desensitization of the ACTH response to AVP

The first series of experiments was designed to determine the concentrations and durations of AVP treatment which cause desensitization. The protocol for these experiments was based on that used by Weiss et al. (1995) to investigate desensitization of gonadotrophin-releasing hormone $(\mathrm{GnRH})$-stimulated luteinizing hormone secretion. In this procedure perifused cells are repeatedly stimulated with short pulses of a secretagogue at a high concentration. The interval between each of these pulses is relatively long to minimize the effects of one pulse on the next. In order to induce desensitization one of these pulses is immediately preceded by a treatment with a lower concentration of the secretagogue. The extent of desensitization is assessed quantitatively for each perifusion column by expressing the response to this pretreated pulse as a percentage of the mean of the responses to the other pulses, which act as controls.

Using the multi-column perifusion system, dispersed ovine anterior pituitary cells were stimulated with $5 \mathrm{~min}$ pulses of $100 \mathrm{nM}$ AVP after 100, 180 and $260 \mathrm{~min}$ of perifusion. Responses to consecutive AVP pulses had a tendency to decrease. Compared with the first pulse the responses to the second and third pulses were $99 \cdot 1 \pm 3 \cdot 2 \%$ $(n=3$, not significant (NS), one-way ANOVA with Dunnett's test $)$ and $80 \cdot 3 \pm 5 \cdot 5 \% \quad(n=3$, NS, one-way ANOVA with Dunnett's test) respectively (Fig. 1A). Since the mean of the responses to the first and third pulses was no different from the response to the second pulse $(n=9$, NS, Student's $t$-test $)$ it was assigned as control (100\%). Pretreatment for 25 min with $5 \mathrm{nM}$ AVP prior to the second $100 \mathrm{nM}$ AVP pulse (Fig. 1B) reduced the response to $62.1 \pm 3.7 \% \quad(n=7, \quad P<0.0001, \quad t$-test $)$ of control. This pretreatment had no effect on the response to the third $100 \mathrm{nM}$ AVP pulse when this was compared with the corresponding pulse in columns where there was no AVP pretreatment ( $n=3$, NS, $t$-test).

The reduction in response to AVP following pretreatment with AVP seen in Fig. 1B reflected a specific desensitization of the cells to AVP and was not due to depletion of ACTH stores. This was demonstrated by replacing the three AVP pulses with $5 \mathrm{~min}$ pulses of $50 \mathrm{mM} \mathrm{KCl}$. As shown in Fig. 2A there was no significant difference between the magnitude of the response to three consecutive pulses of $50 \mathrm{mM} \mathrm{KCl}$ : the responses to the second and third pulses were $93 \cdot 3 \pm 3 \cdot 5 \%(n=3$, NS,
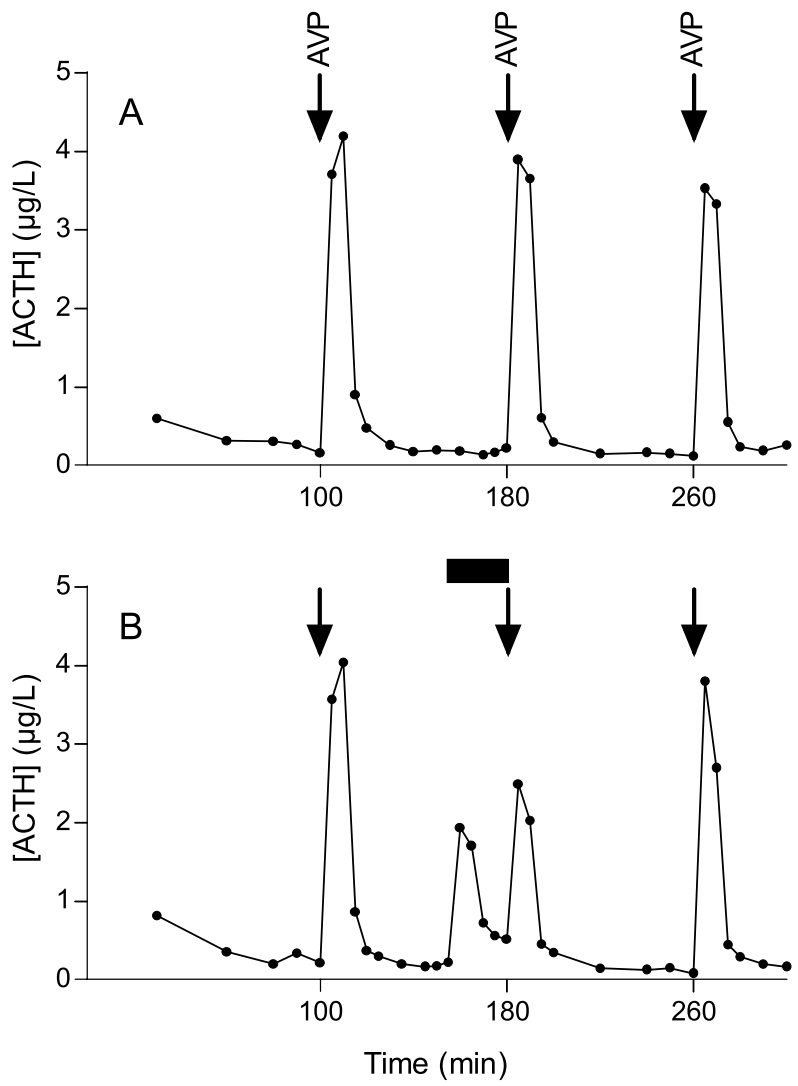

Figure 1 Desensitization of the ACTH response to AVP. Representative data are shown from two independent columns of the perifusion system illustrating the protocol used in these experiments. (A) Cells were treated with 5 min pulses of $100 \mathrm{nM}$ AVP after 100, 180 and 260 min of perifusion (indicated by arrows). (B) To induce desensitization the second pulse was preceded by a pretreatment with $5 \mathrm{nM}$ AVP for 25 min (indicated by the black bar).

one-way ANOVA with Dunnett's test) and $83.9 \pm 4.5 \%$ $(n=3$, NS, one-way ANOVA with Dunnett's test) of the response to the first pulse. However, pretreatment with $5 \mathrm{nM}$ AVP for $25 \mathrm{~min}$ prior to the second pulse did not cause any reduction in response to the second $\mathrm{KCl}$ pulse compared with the control (Fig. 2B). In fact, there was a significant increase in ACTH secretion in response to the $\mathrm{KCl}$ pulse following AVP pretreatment (ACTH secretion increased to $198 \cdot 8 \pm 18 \cdot 4 \%$ compared with control, $n=3$, $P<0 \cdot 05, t$-test). This is consistent with a report by Le Beau \& Mason (1998) who found that AVP and $\mathrm{KCl}$ were synergistic at low concentrations. Overall, these results clearly show that the reduction in response to an AVP pulse following pretreatment is the result of an AVPspecific desensitization process.

\section{Effect of concentration of AVP pretreatment on desensitization}

To investigate the concentration-dependency of desensitization, the duration of the pretreatment was held 

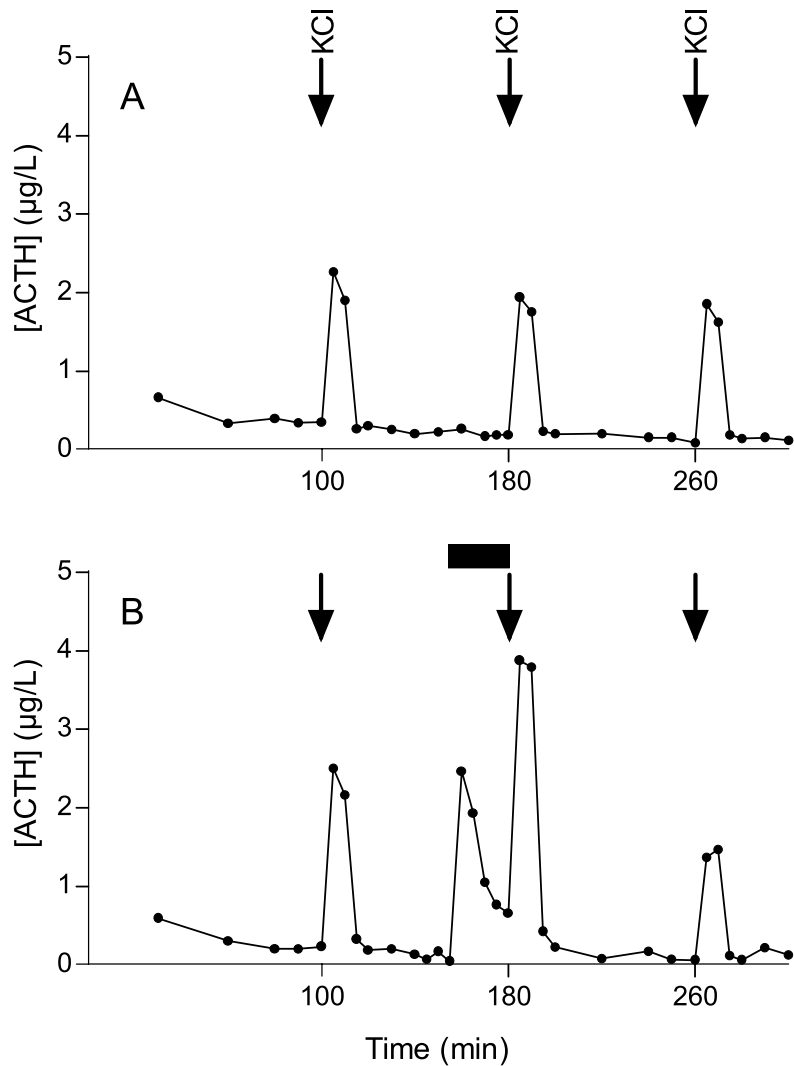

Figure 2 Effect of treatment with $\mathrm{KCl}$ on $\mathrm{ACTH}$ secretion. (A) Cells were treated with 5 min pulses of $50 \mathrm{mM} \mathrm{KCl}$ after 100, 180 and $260 \mathrm{~min}$ of perifusion (indicated by arrows). (B) Pretreatment of the second $\mathrm{KCl}$ pulse with $5 \mathrm{nM}$ AVP for 25 min (indicated by black bar) resulted in an increase in ACTH secretion compared with the control pulses.

constant at 25 min while the AVP pretreatment concentration applied to different columns was varied from $0 \cdot 1$ to $50 \mathrm{nM}$. AVP pretreatment desensitized the response to a subsequent AVP pulse in a concentration-dependent manner. A sigmoidal concentration-response curve was fitted to the data yielding an $r^{2}$ of 0.93 and a predicted value for $50 \%$ desensitization $\left(\mathrm{IC}_{50}\right)$ of the ACTH response of $6.54 \mathrm{nM}$ AVP. The lowest concentration of AVP tested capable of causing a significant reduction in response was $2 \cdot 0 \mathrm{nM}(n=3, P<0 \cdot 02, t$-test). Results are summarized in Fig. 3. ACTH release following pretreatment with $50 \mathrm{nM}$ AVP was maintained at a plateau by the second AVP pulse rather than the pulse causing a response peak as seen at lower pretreatment concentrations.

\section{Effect of duration of AVP pretreatment on desensitization}

The degree of desensitization of the response to an AVP pulse was also found to be dependent on the duration of the pretreatment. A similar protocol to that described above was used except that the concentration of the

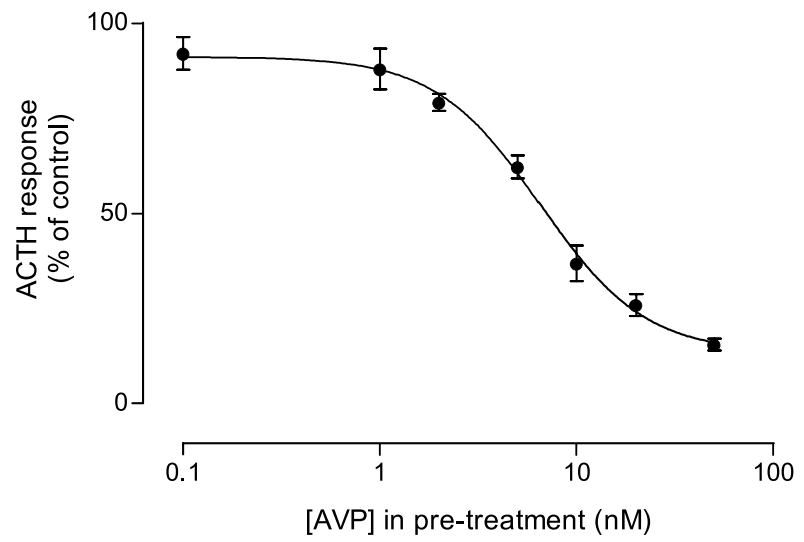

Figure 3 Concentration-dependency of the desensitization of the $\mathrm{ACTH}$ response to AVP, determined using the experimental protocol shown in Fig. 1. The ACTH response to the second AVP pulse was expressed as a percentage of the control pulses. The concentrations used for the 25 min pretreatment are plotted on a log scale. Data are means \pm S.E.M. $(n=2-9$ for each treatment).

pretreatment was held constant at $5 \mathrm{nM}$ AVP while the duration varied from 0 to $25 \mathrm{~min}$. A pretreatment for as little as 5 min resulted in a significant reduction in the response to the second AVP pulse compared with the control (to $78 \cdot 5 \pm 1 \cdot 5 \%, n=3, P<0 \cdot 005, t$-test). A greater reduction in the response to the second AVP pulse (to $60 \cdot 6 \pm 8 \cdot 6 \%, n=3, P<0 \cdot 05, t$-test) was observed when the duration of the $5 \mathrm{nM}$ AVP pretreatment was increased to $10 \mathrm{~min}$. However, extending the pretreatment period beyond $10 \mathrm{~min}$ did not result in any further increase in the magnitude of desensitization. Data are summarized in Fig. 4.

\section{Resensitization of the ACTH response to AVP}

Perifused anterior pituitary cells were clearly quite sensitive to desensitization of the ACTH response to AVP. To characterize this process further, the ability of desensitized cells to recover their responsiveness to AVP was investigated. Since it was anticipated that the effects of desensitization would take somewhat longer to be reversed than they did to occur, an experimental protocol different from that used to investigate the time- and concentrationdependency of desensitization was employed. Cells were stimulated with a single 5 min pulse of $100 \mathrm{nM}$ AVP after $200 \mathrm{~min}$ of perifusion. This pulse was preceded by a $15 \mathrm{~min}$ pretreatment with $10 \mathrm{nM}$ AVP. Unlike the experimental protocol used in the first series of experiments the cells were allowed a recovery period of up to $80 \mathrm{~min}$ between the pretreatment and the AVP pulse. During this recovery period they were perifused with buffer alone. In order to assess quantitatively the extent of resensitization, the response of the pretreated cells to $100 \mathrm{nM}$ AVP was expressed as a percentage of the mean 


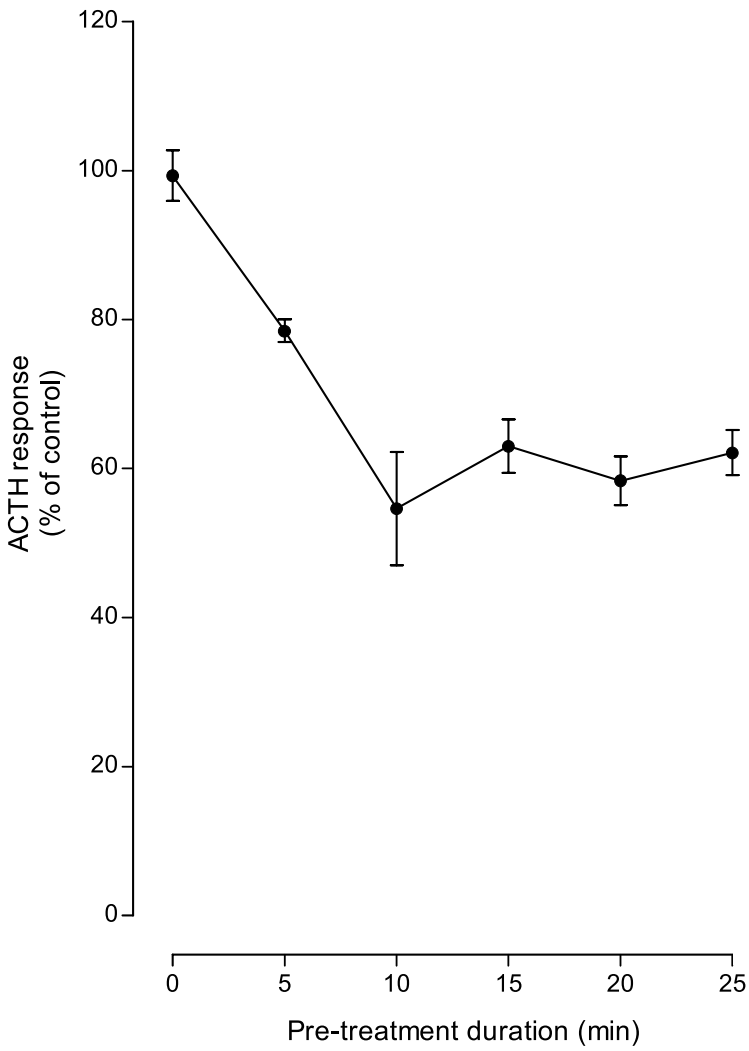

Figure 4 Time-dependency of the desensitization of the ACTH response to AVP. The ACTH response to the second AVP pulse, as a percentage of the control pulses, is plotted against the duration of the AVP pretreatment. The concentration of AVP used for the pretreatment was $5 \mathrm{nM}$. Data are means \pm S.E.M. $(n=3-7$ for each treatment).

response of control cells (i.e. cells that had not been pretreated) to a $100 \mathrm{nM}$ AVP pulse.

When the AVP pulse was applied immediately upon termination of the pretreatment (i.e. 0 min recovery time) the magnitude of the response to the test pulse was reduced to $36 \cdot 7 \pm 5 \cdot 4 \% \quad(n=7, \quad P<0 \cdot 01, \quad$ one-way ANOVA with Dunnett's test) of controls that were not pretreated. When the cells were allowed a $10 \mathrm{~min}$ recovery period between the pretreatment and the test pulse there was a partial recovery in response to $67 \cdot 3 \pm 7 \cdot 6 \% \quad(n=8, \quad P<0 \cdot 01$, Dunnett's test $)$ of control. Recovery was complete after $40 \mathrm{~min}$. Data are summarized in Fig. 5.

\section{Desensitization of the ACTH response to $C R H$}

Kinetic analysis of data obtained with perifused rat (Watanabe \& Orth 1987, Won et al. 1990) and sheep (Mason 1988, Mason et al. 1998) anterior pituitary cells has shown that AVP-stimulated ACTH secretion peaks rapidly and then falls almost as rapidly to a low $(\sim 25 \%$ of

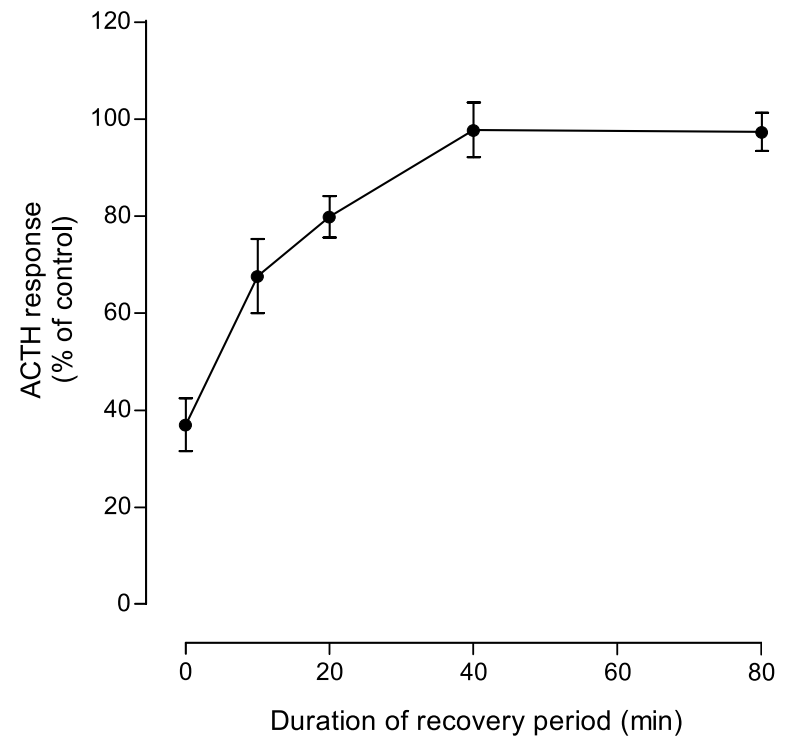

Figure 5 Time-course of resensitization of the ACTH response to AVP. The ACTH response after pretreatment with $10 \mathrm{nM}$ AVP for $15 \mathrm{~min}$ is plotted against the duration of the recovery period (i.e. the period of time between the pretreatment and the AVP pulse during which the cells were perifused with medium alone). Data are means \pm S.E.M. $(n=7-15$ for each treatment).

peak), sustained plateau, despite continued AVP perifusion (e.g. see the response to the AVP pretreatment in Fig. 1B). In contrast, $\mathrm{CRH}$-stimulated $\mathrm{ACTH}$ release reaches a maximum somewhat less rapidly and then remains constant, or declines very slowly, throughout the CRH exposure (e.g. see the response to the $\mathrm{CRH}$ pretreatment in Fig. 7C). These differences in the ACTH secretion profiles may indicate a slower and/or lower magnitude of desensitization for $\mathrm{CRH}$ than AVP. In view of the possibility that desensitization of the ACTH response to $\mathrm{CRH}$ is a relatively slow process, initial experiments were done using a static culture system. Cells were exposed to $1 \mathrm{nM} \mathrm{CRH}$ during a $90 \mathrm{~min}$ test incubation following pretreatment in the absence or presence of $\mathrm{CRH}(0 \cdot 001-$ $100 \mathrm{nM}$ ) for times ranging from 30 to $360 \mathrm{~min}$. CRH pretreatment resulted in a concentration- and durationdependent reduction in the ACTH response to subsequent stimulation with CRH (Fig. 6A and B). For example, with a 60 min pretreatment (Fig. 6A) the lowest concentration of $\mathrm{CRH}$ tested that was capable of causing a significant reduction in response was $0.1 \mathrm{nM}(n=4, P<0 \cdot 05, t$-test $)$. When a pretreatment $\mathrm{CRH}$ concentration of $10 \mathrm{nM}$ was used (Fig. 6B) 60 min was the minimum duration capable of causing a significant reduction in response $(n=4$, $P<0 \cdot 05, t$-test).

Perifusion was used in subsequent experiments to define more precisely the threshold concentration and duration required for $\mathrm{CRH}$ desensitization, and to enable easier comparison of the characteristics of AVP and $\mathrm{CRH}$ 

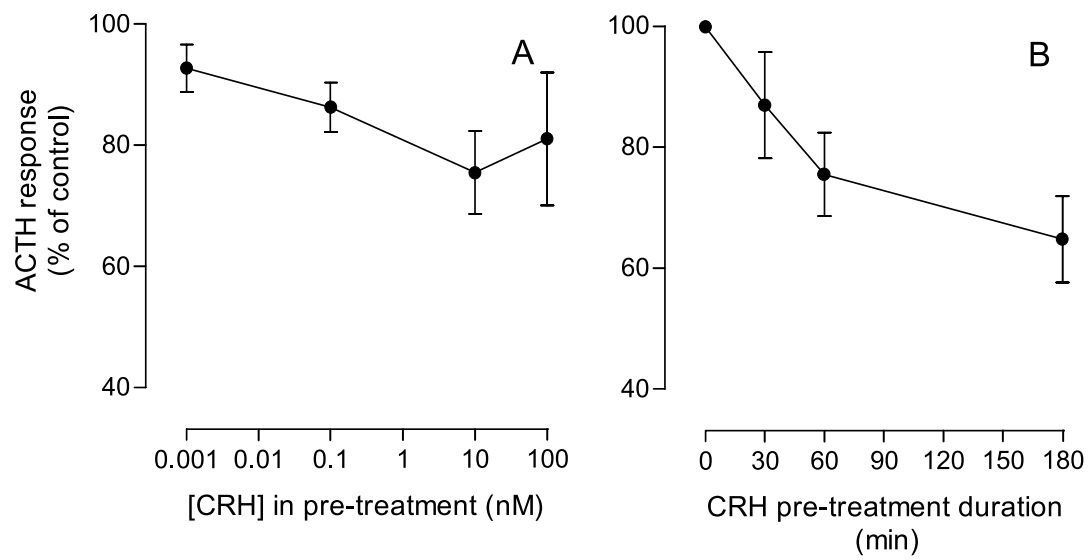

Figure 6 Desensitization of the ACTH response to $\mathrm{CRH}$ in static culture. (A) The effect of a 60 min pretreatment with $\mathrm{CRH}$, at the concentrations shown, on the ACTH response to a subsequent 90 min test incubation with $1 \mathrm{nM} \mathrm{CRH}$. (B) The effect of pretreatment with $10 \mathrm{nM} \mathrm{CRH}$ for the indicated times on the response to a subsequent $1 \mathrm{nM} \mathrm{CRH}$ stimulation. Data are means \pm S.E.M. ( $n=3-4$ for each treatment).

desensitizations. Because of the relative slowness of the $\mathrm{CRH}$ desensitization seen in static culture, the "three pulse' protocol used to investigate AVP desensitization was not used for CRH. Instead cells were stimulated with a single pulse of $10 \mathrm{nM} \mathrm{CRH}$ after $200 \mathrm{~min}$ of perifusion. This pulse was immediately preceded by CRH treatments of either 25 or 50 min duration and $0 \cdot 1$ or $1 \mathrm{nM}$ concentration. The effect of these pretreatments on the response to the pulse was assessed by expressing the response to the $\mathrm{CRH}$ pulse as a percentage of the mean response of control cells (i.e. cells that had not been pretreated) to a $10 \mathrm{nM}$ $\mathrm{CRH}$ pulse. In the control columns treatment with the $10 \mathrm{nM}$ CRH pulse caused a broad peak of ACTH secretion (Fig. 7A). In test columns cells were pretreated with 0.1 or $1.0 \mathrm{nM} \mathrm{CRH}$ for either 25 or $50 \mathrm{~min}$ immediately prior to the CRH pulse (Fig. 7B and C). Analysis of the data by two-way ANOVA showed that both the concentration $(P<0.01)$ and duration $(P<0.001)$ of pretreatment were significant factors affecting the extent of desensitization observed. Further analysis showed that neither of the two $0.1 \mathrm{nM} \mathrm{CRH}$ pretreatments was capable of causing a significant reduction in the $\mathrm{ACTH}$ response to a subsequent $\mathrm{CRH}$ pulse (NS, two-way ANOVA with Dunnett's test; $n=9$ and $n=8$ respectively for the 25 and 50 min pretreatments). Significant decreases in the response to the test pulse were observed when the CRH pretreatment concentration was increased to $1 \mathrm{nM}$ : compared with controls that were not pretreated the response to the pulse was reduced to $71 \cdot 8 \pm 6 \cdot 5 \%(n=9, P<0 \cdot 05$, Dunnett's test) of control after a 25 min pretreatment and to $52 \cdot 4 \pm 7 \cdot 5 \%(n=9, P<0 \cdot 01$, Dunnett's test $)$ after a 50 min pretreatment. Results are summarized in Fig. 8.

\section{Resensitization of the ACTH response to $C R H$}

The time required for resensitization of the ACTH response to $\mathrm{CRH}$ to occur was investigated in a manner similar to that used to investigate resensitization to AVP. Desensitization was induced by treatment with $1 \mathrm{nM}$ $\mathrm{CRH}$ for $50 \mathrm{~min}$. A recovery period of up to $100 \mathrm{~min}$ (during which cells were treated with basal KR) was allowed between the end of this pretreatment and the start of a $5 \mathrm{~min} \mathrm{CRH}(10 \mathrm{nM})$ test pulse. When the pretreatment immediately preceded the pulse the response was reduced to $54 \cdot 0 \pm 6 \cdot 2 \%(n=6, P<0 \cdot 01$, Dunnett's test $)$ of control. Increasing the duration of the recovery period resulted in a progressive increase in ACTH responsiveness to the $\mathrm{CRH}$ pulse, returning to control levels after a $100 \mathrm{~min}$ recovery period. Results are summarized in Fig. 9.

Effect of CRH treatment on desensitization of the ACTH response to $A V P$

$\mathrm{CRH}$ and AVP both contribute to the regulation of ACTH secretion in vivo. Since it has been suggested that $\mathrm{CRH}$ may function as a permissive signal, setting the overall responsiveness of the corticotroph, while AVP is the main dynamic hypothalamic ACTH-releasing factor (Antoni 1993, Evans et al. 1996) we wished to determine whether a constant perifusion with CRH could overcome or enhance the desensitizing effects of AVP. Desensitization of the ACTH response to AVP was induced and assessed as shown in Fig. 1A and B, with the second of the three $100 \mathrm{nM}$ AVP pulses being immediately preceded by a $15 \mathrm{~min}$ pretreatment with $5 \mathrm{nM}$ AVP. As expected, this pretreatment markedly reduced the response (to $66 \cdot 3 \pm 3.7 \%, n=10, P<0 \cdot 0001$, one-way ANOVA with Tukey's test). To investigate the effect of $\mathrm{CRH}$ on this AVP-induced desensitization, cells were continuously perifused with a low level of $\mathrm{CRH}$ $(0.01 \mathrm{nM})$ beginning at $80 \mathrm{~min}$ and continuing until the end of the experiment. Although this concentration of 


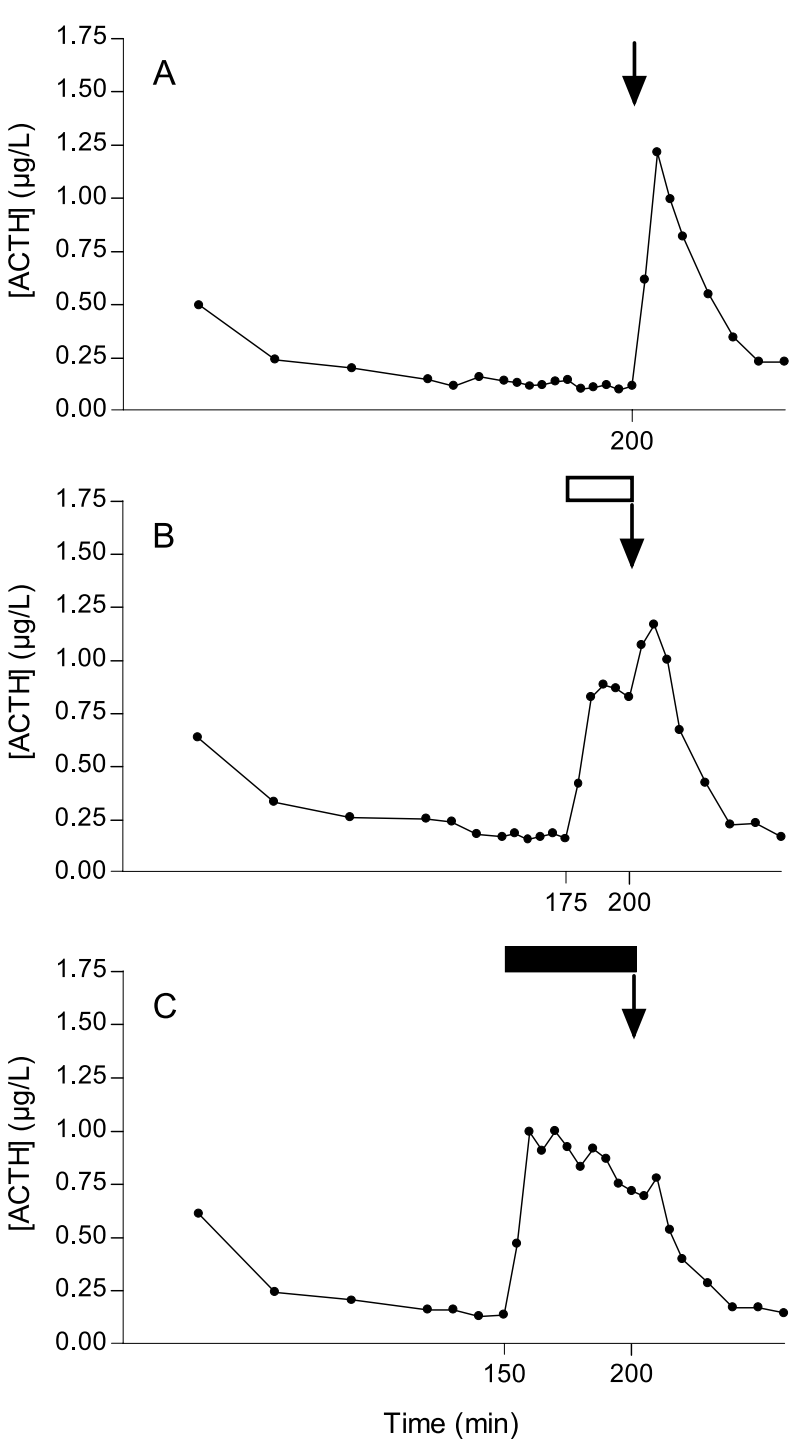

Figure 7 Desensitization of the $\mathrm{ACTH}$ response to $\mathrm{CRH}$ in multi-column perifusion. Representative data are shown from three independent columns of the perifusion system illustrating the protocol used in these experiments. (A) Cells were treated with a single 5 min pulse of $10 \mathrm{nM}$ CRH after 200 min of perifusion (indicated by arrows). To induce desensitization this pulse was immediately preceded by a pretreatment with a lower concentration of $\mathrm{CRH}$. (B) Twenty-five minute pretreatment with $0 \cdot 1 \mathrm{nM}$ CRH (open bar). (C) Fifty minute pretreatment with $1 \mathrm{nM}$ $\mathrm{CRH}$ (black bar).

$\mathrm{CRH}$ was insufficient on its own to stimulate ACTH release, it was able to synergize with AVP causing enhanced ACTH secretion. Despite this effect on ACTH release, constant $\mathrm{CRH}$ perifusion did not overcome or enhance AVP-induced desensitization: in the presence of $\mathrm{CRH}$, pretreatment with $5 \mathrm{nM}$ AVP for 15 min reduced the response to $62 \cdot 0 \pm 1 \cdot 9 \%(n=13, P<0 \cdot 0001$, Tukey's test) of controls that were not pretreated, but the magni-

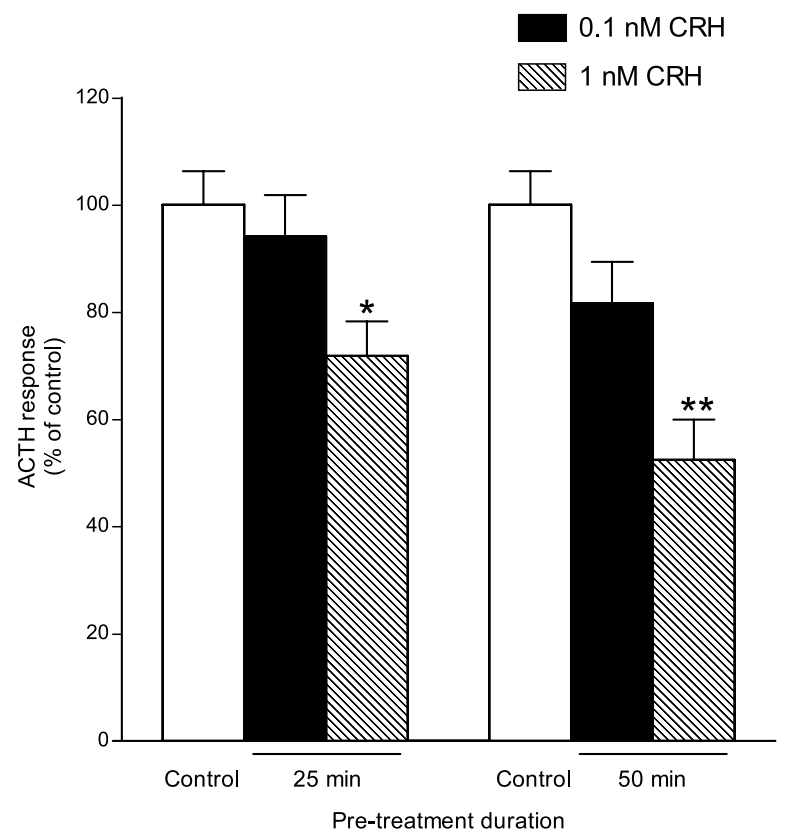

Figure 8 Concentration- and time-dependency of desensitization of the ACTH response to $\mathrm{CRH}$ in multi-column perifusion. The $\mathrm{ACTH}$ response to $\mathrm{CRH}$ following pretreatment with $\mathrm{CRH}$ at the concentrations and durations indicated is shown. Data are means \pm S.E.M. $(n=8-9$ for each treatment). Asterisks indicate statistically significant differences between the pretreated and control values $\left({ }^{*} P<0 \cdot 05 ;{ }^{*} P<0 \cdot 01\right)$.

tude of this desensitization was not significantly different from that observed in the absence of $\mathrm{CRH}$ (difference $4 \cdot 3 \%$, NS, Tukey's test). Results are summarized in Fig. 10.

\section{Discussion}

This study has shown that the ACTH response of cultured ovine anterior pituitary cells undergoes rapid desensitization during treatment with $\mathrm{CRH}$ and AVP. The characteristics of the two desensitization processes differ suggesting that they contribute differently to the physiological regulation of ACTH secretion.

Earlier in vitro studies reported desensitization to AVP following stimulation with AVP at either high concentrations or for long periods of time (Holmes et al. 1984, Antoni et al. 1985, Evans et al. 1988, Castro 1993). In contrast, secretion of AVP into the hypophyseal portal circulation is highly pulsatile, with the AVP concentration of pulses normally being below $6 \mathrm{nM}$ and secretory events lasting less than 30 min (Caraty et al. 1988, 1990, Engler et al. 1989, Battaglia et al. 1998, Dadoun et al. 1998). In this study desensitization of the ACTH response to AVP was found to occur following AVP treatment at concentrations and durations that more closely match those of 


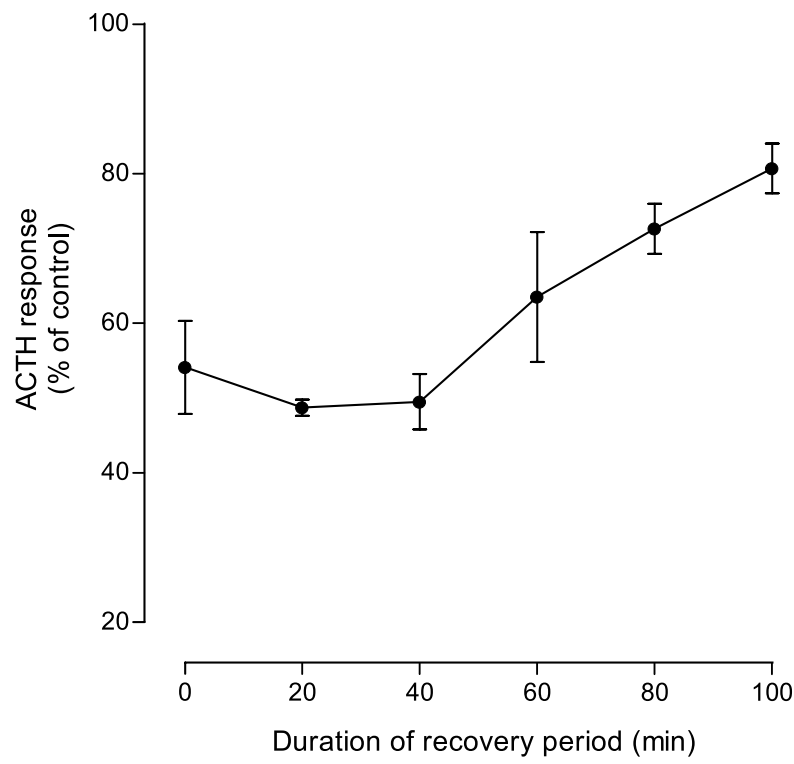

Figure 9 Time-course of resensitization of the ACTH response to $\mathrm{CRH}$. The ACTH response after pretreatment with $1 \mathrm{nM} \mathrm{CRH} \mathrm{for}$ $50 \mathrm{~min}$ is plotted against the duration of the recovery period (i.e. the period of time between the pretreatment and the CRH pulse during which the cells were perifused with medium alone). Data are means \pm S.E.M. ( $n=2-6$ for each treatment).

endogenous AVP pulses. Pretreatment with AVP at concentrations as low as $2 \mathrm{nM}$ was capable of eliciting a significant reduction in response to a subsequent $100 \mathrm{nM}$ AVP pulse $\left(\mathrm{IC}_{50}=6.54 \mathrm{nM}\right)$ and the maximal desensitization to $5 \mathrm{nM}$ AVP was reached with a $10 \mathrm{~min}$ pretreatment. The response returned to a level not significantly different from that of the controls after a recovery period of $40 \mathrm{~min}$.

The comparison of our results with these endogenous AVP pulse characteristics is interesting. Our data suggest that while most endogenous AVP pulses would be long enough to cause desensitization, because of their low concentrations this would only be partial. This suggests that the role of desensitization is not to prevent ACTH secretion, but rather to limit the maximum secretory response to AVP. If this were the case, it would suggest that corticotrophs have an intrinsic set-point, beyond which they become refractory to further stimulation with AVP. Furthermore, the rapidity of the desensitization of the ACTH response to AVP might act to limit the duration of secretory episodes. Together these two properties of the desensitization process could result in a stereotyping of ACTH pulse amplitude and duration in response to AVP stimulation (Leng \& Brown 1997). Weiss et al. (1995) used a similar experimental design to investigate the desensitization of perifused rat anterior pituitary cells to GnRH and found a qualitatively similar relationship between in vitro desensitization and endogenous pulse characteristics: endogenous $\mathrm{GnRH}$ pulses

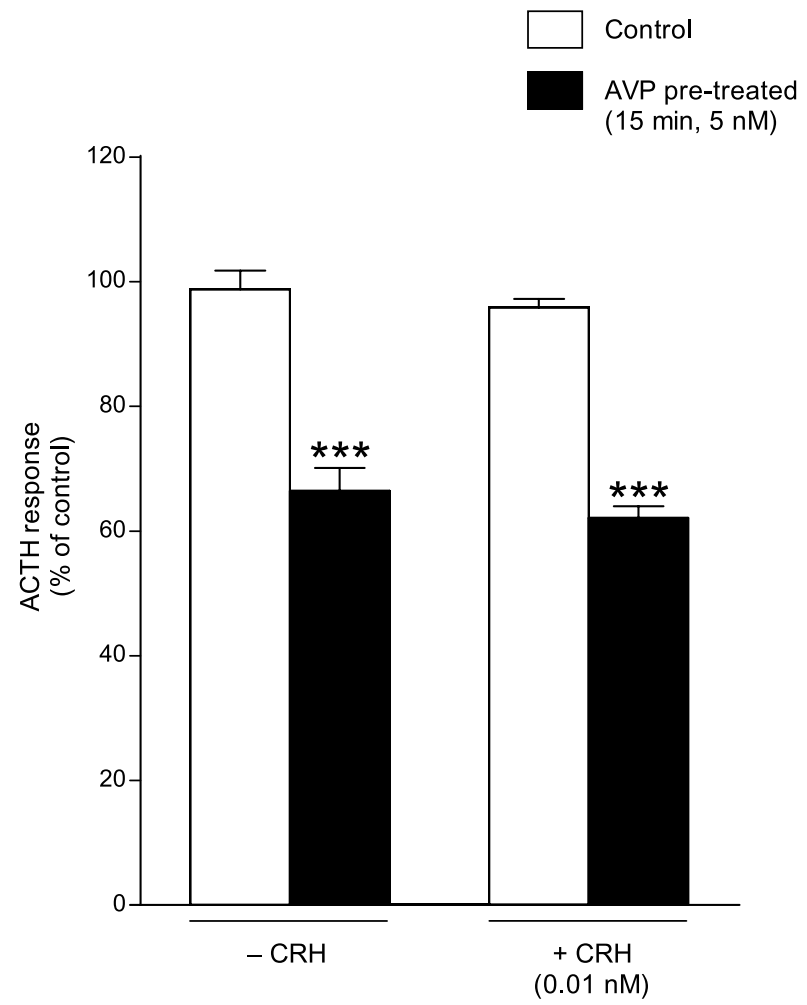

Figure 10 Effect of $\mathrm{CRH}$ on desensitization of the $\mathrm{ACTH}$ response to AVP. Data show the ACTH response to an AVP pulse in either the presence or absence of a 0.01 nM CRH 'background' when the pulse was not preceded by a pretreatment (controls) and when it was immediately preceded by a 15 min pretreatment with $5 \mathrm{nM}$ AVP. Data are means \pm S.E.M. ( $n=6-10$ for each treatment). Asterisks indicate statistically significant differences between the pretreated and control values $\left({ }^{* *} P<0 \cdot 001\right)$.

would have been long enough although not of sufficient concentration to evoke desensitization.

The ACTH response of sheep anterior pituitary cells to CRH appears to be considerably less susceptible to desensitization than the response to AVP. In perifusion experiments, significant desensitization following pretreatments of 25 or 50 min duration required a CRH concentration of $>0 \cdot 1 \mathrm{nM}$. Similar results were obtained in static culture experiments. We have observed with ovine anterior pituitary cells that $\mathrm{CRH}$ is a more potent stimulator of ACTH secretion than AVP; for CRH the threshold and maximal concentrations were $0 \cdot 01$ and $\geq 1 \mathrm{nM}$ respectively, compared with values of 1 and $\geq 100 \mathrm{nM}$ for AVP (AJ Johnson \& DR Mason, unpublished observations). Thus the ACTH response to CRH was relatively less susceptible to homologous desensitization than the response to AVP. This difference in the regulation of the responses to the two hormones suggests that they might have distinct physiological roles in the regulation of ACTH secretion and are probably mediated via distinct molecular processes. 
In contrast to AVP, the CRH concentrations and durations at which desensitization occurred were not within the endogenous ranges. In the sheep, CRH pulses during acute stress rarely last more than $30 \mathrm{~min}$, with maximal portal plasma concentrations being less than $\sim 0.4 \mathrm{nM}$ (Caraty et al. 1988, 1990). Our data are inconsistent with evidence provided by Evans et al. (1988) indicating that the minimal concentration required for $\mathrm{CRH}$-induced desensitization to repetitive $10 \mathrm{~min} \mathrm{CRH}$ pulses in sheep anterior pituitary cells is $0.2 \mathrm{nM}$. This concentration corresponds with the peak CRH level seen in portal blood during acute haemorrhage, and is less than the level seen with insulin-induced hypoglycaemia. The differences between the results of the two studies may be a reflection of the different protocols used to examine $\mathrm{CRH}$-induced desensitization. In any event, endogenous $\mathrm{CRH}$ pulses are unlikely to cause more than minimal desensitization during acute stress. However, if pituitary portal CRH concentrations are elevated during chronic stress or other pathophysiological conditions this could result in desensitization of pituitary ACTH responses to this hormone.

In view of the proposal that AVP is the primary acute signal for ACTH release and CRH acts to set the gain of corticotroph responsiveness to fluctuations in AVP (but is not a major regulator of short term fluctuations in ACTH secretion) (Antoni 1993, Evans et al. 1996), we examined the effect of CRH on AVP-induced desensitization. We found that the presence of $\mathrm{CRH}$ did not affect the extent of desensitization of the response to the second AVP pulse, which was reduced by $\sim 40 \%$ following AVP pretreatment. Thus a low-level 'background' of CRH neither protected the ACTH response from AVP-induced desensitization nor enhanced the desensitization process. However, given the synergistic effect of $\mathrm{CRH}$ on AVPstimulated ACTH secretion it seems certain that any desensitization of the response of corticotrophs to $\mathrm{CRH}$ could have significant consequences for AVP-induced $\mathrm{ACTH}$ secretion and thus stress-induced ACTH secretion.

The characteristics of the desensitization of the ACTH response to $\mathrm{CRH}$ and AVP give some clues to the mechanisms that underlie it. Both desensitizations occurred within minutes of stimulation and were readily reversible. These characteristics are typical of desensitization processes mediated by receptor uncoupling (Lohse 1993). Commonly uncoupling is mediated by receptor phosphorylation which, either directly or indirectly, prevents receptors from interacting with their associated $G$ proteins (Lohse 1993). It has recently been reported that $G$ protein-coupled receptor kinase (GRK) 3 is involved in desensitization of human CRH receptors of the sub-type found in the pituitary (i.e. CRH-R1) (Dautzenberg et al. 2001). It is possible that similar mechanisms are involved in regulating ovine pituitary CRH-R1. Phosphorylation of the pituitary AVP (V1b) receptor has not been reported to date although the receptor terminus contains one proximal GRK consensus motif and two centrally located protein kinase $\mathrm{C}$ consensus motifs indicating that desensitization could occur via phosphorylation. Involvement of other mechanisms, such as receptor sequestration, cannot be excluded. The rapid desensitization observed in our experiments is more likely to be involved in regulating the acute response to AVP than in altering the responsiveness of the corticotroph during chronic stress.

In summary, it has been shown that the ACTH response to both CRH and AVP undergoes desensitization. The concentrations and durations of AVP exposure which are capable of eliciting desensitization suggest that this desensitization process may play an important physiological role in regulating ACTH secretion from the anterior pituitary. The role of CRH desensitization in the regulation of the hypothalamic-pituitaryadrenal axis is less clear, but if, as has been suggested, $\mathrm{CRH}$ acts to set corticotroph gain, any change in responsiveness to this neuropeptide might play an important role in the physiological control of ACTH secretion.

\section{Acknowledgements}

The authors wish to thank Professor Richard Donald for the ACTH antiserum, and the late Dr C H Li for highly purified ovine ACTH. We also thank Drs Greti Aguilera, Margaret Evans and Peter Lipton for critical reading of the manuscript. This work was supported in part by grants from the Canterbury Medical Research Foundation (Project Grant 99028) and the University of Canterbury (Grants 2314290 and U6405) and by an A M I McKessar Fellowship to A H from the Canterbury Medical Research Foundation.

\section{References}

Aguilera G 1994 Regulation of pituitary ACTH secretion during chronic stress. Frontiers in Neuroendocrinology 15 321-350.

Antoni FA 1986 Hypothalamic control of adrenocorticotropin secretion: advances since the discovery of 41-residue corticotropinreleasing factor. Endocrine Reviews 7 351-378.

Antoni FA 1993 Vasopressinergic control of pituitary adrenocorticotropin secretion comes of age. Frontiers in Neuroendocrinology 14 76-122.

Antoni FA, Holmes MC \& Kiss J 1985 Pituitary binding of vasopressin is altered by experimental manipulations of the hypothalamo-pituitary-adrenocortical axis in normal as well as homozygous (di/di) Brattleboro rats. Endocrinology 117 1293-1299.

Battaglia DF, Brown ME, Krasa HB, Thrun LA, Viguié C \& Karsch FJ 1998 Systemic challenge with endotoxin stimulates corticotropin-releasing hormone and arginine vasopressin secretion into hypophyseal portal blood: coincidence with gonadotropinreleasing hormone suppression. Endocrinology 139 4175-4181.

Caraty A, Grino M, Locatelli A \& Oliver C 1988 Secretion of corticotropin releasing factor (CRF) and vasopressin into the hypophysial portal blood of conscious, unrestrained rams. Biochemical and Biophysical Research Communications 155 841-849. 
Caraty A, Grino M, Locatelli A, Guillaume V, Boudouresque F, Conte-Devolx B \& Oliver C 1990 Insulin-induced hypoglycemia stimulates corticotropin-releasing factor and arginine vasopressin secretion into hypophysial portal blood of conscious, unrestrained rams. Journal of Clinical Investigation 85 1716-1721.

Castro MG 1993 Effects of corticotrophin-releasing factor and arginine-vasopressin on proopiomelanocortin (POMC) mRNA levels, release and storage of adrenocorticotrophin from mouse anterior pituitary cells. Comparative Biochemistry and Physiology. A: Comparative Physiology 104 105-112.

Dadoun F, Guillaume V, Sauze N, Farisse J, Velut JG, Orsoni JC, Gaillard R \& Oliver C 1998 Effect of endotoxin on the hypothalamic-pituitary-adrenal axis in sheep. European Journal of Endocrinology 138 193-197.

Dautzenberg FM, Braun S \& Hauger RL 2001 GRK3 mediates desensitization of $\mathrm{CRF}_{1}$ receptors: a potential mechanism regulating stress adaptation. American Journal of Physiology 280 R935-R946.

De Keyzer Y, Auzan C, Lenne F, Chérif B, Thibonnier M, Bertagna X \& Clauser E 1994 Cloning and characterization of the human V3 pituitary vasopressin receptor. FEBS Letters 356 215-220.

Engler D, Pham T, Fullerton MJ, Ooi G, Funder JW \& Clarke IJ 1989 Studies of the secretion of corticotropin-releasing factor and arginine vasopressin into the hypophysial-portal circulation of the conscious sheep: I. Effect of an audiovisual stimulus and insulininduced hypoglycemia. Neuroendocrinology 49 367-381.

Evans MJ, Brett JT, McIntosh RP, McIntosh JEA, Roud HK, Livesey JH \& Donald RA 1985 The effect of various corticotropin-releasing factor trains on the release of adrenocorticotropin, $\beta$-endorphin and $\beta$-lipotropin from perifused ovine anterior pituitary cells. Endocrinology 117 893-899.

Evans MJ, Brett JT, McIntosh RP, McIntosh JEA, McLay JL, Livesey JH \& Donald RA 1988 Characteristics of the ACTH response to repeated pulses of corticotrophin-releasing factor and arginine vasopressin in vitro. Journal of Endocrinology 117 387-395.

Evans MJ, Marshall AG, Kitson NE, Summers K \& Donald RA 1993 Factors affecting ACTH release from perifused equine anterior pituitary cells. Journal of Endocrinology 137 391-401.

Evans MJ, Mulligan RS, Livesey JH \& Donald RA 1996 The integrative control of adrenocorticotropin secretion: a critical role for corticotrophin-releasing hormone. Journal of Endocrinology 148 475-483.

Familari M, Smith AI, Smith R \& Funder JW 1989 Arginine vasopressin is a much more potent stimulus to ACTH release from ovine anterior pituitary cells than ovine corticotropin-releasing factor. Neuroendocrinology 50 152-157.

Hoffman AR, Ceda G \& Reisine TD 1985 Corticotropin-releasing factor desensitization of adrenocortiotropic hormone release is augmented by arginine vasopressin. Journal of Neuroscience $\mathbf{5}$ 234-242.

Holmes MC, Antoni FA \& Szentendrei T 1984 Pituitary receptors for corticotropin-releasing factor: no effect of vasopressin on binding or activation of adenylate cyclase. Neuroendocrinology 39 162-169.

Koch B \& Lutz-Bucher B 1985 Specific receptors for vasopressin in the pituitary gland: evidence for down-regulation and desensitization to adrenocorticotropin-releasing factors. Endocrinolog $y$ 116 671-676.

Le Beau AP \& Mason DR 1994 The effects of a chemically diverse range of calcium channel antagonists on the AVP-stimulated ACTH response in ovine corticotrophs. Cell Calcium 16 47-58.

Le Beau AP \& Mason DR 1998 Interaction between arginine vasopressin- and raised extracellular potassium-stimulated pathways in adrenocorticotropin secretion. Life Sciences 63 2233-2242.
Leng G \& Brown D 1997 The origins and significance of pulsatility in hormone secretion from the pituitary. Journal of Neuroendocrinology 9 493-513.

Livesey JH \& Donald RA 1982 Prevention of adsorption losses during radioimmunoassay of polypeptide hormones: effectiveness of albumins, gelatin, caseins, Tween 20 and plasma. Clinica Chimica Acta 123 193-198.

Lohse MJ 1993 Molecular mechanisms of membrane receptor desensitization. Biochimica et Biophysica Acta 1179 171-188.

Mason DR 1988 The effect of vasopressin, phorbol ester and a calcium ionophore on ACTH release from ovine pituitary cells. Proceedings of the Endocrine Society of Australia 31 S32 (Abstract).

Mason DR, Hassan AMA \& Rothwell SE 1998 Mechanism of desensitization of the adrenocorticotropin response of anterior pituitary cells to corticotropin-releasing hormone. 80th Annual Meeting of the Endocrine Society New Orleans, LA, USA. P3-422 (Abstract).

McFarlane AR, Coghlan J, Tresham J \& Wintour EM 1995 Corticotropin-releasing factor alone, but not arginine vasopressin alone, stimulates the release of adrenocorticotropin in the conscious intact sheep. Endocrinology 136 1821-1827.

McIntosh RP \& McIntosh JE 1983 Influence of the characteristics of pulses of gonadotrophin releasing hormone on the dynamics of luteinizing hormone release from perifused sheep pituitary cells. Journal of Endocrinology 98 411-421.

Reisine TD \& Hoffman A 1983 Desensitization of corticotropinreleasing factor receptors. Biochemical and Biophysical Research Communications 111 919-925.

Thomson M, Chan E-C, Falconer J, Geraghty S, Curryer N, Boulton J \& Smith R 1990 Desensitization of superfused isolated ovine anterior pituitary cells to human corticotropin-releasing factor. Journal of Neuroendocrinology 2 181-187.

Vale W, Vaughan J, Smith M, Yamamoto G, Rivier J \& Rivier C 1983 Effects of synthetic ovine corticotropin-releasing factor, glucocorticoids, catecholamines, neurohypophysial peptides, and other substances on cultured corticotropic cells. Endocrinology 113 $1121-1131$.

Watanabe T \& Orth DN 1987 Detailed kinetic analysis of adrenocorticotropin secretion by dispersed rat anterior pituitary cells in a microperifusion system: effects of ovine corticotropin-releasing factor and arginine vasopressin. Endocrinology 121 1133-1145.

Weiss J, Cote CR, Jameson JL \& Crowley WF 1995 Homologous desensitization of gonadotropin-releasing hormone $(\mathrm{GnRH})$-stimulated luteinizing hormone secretion in vitro occurs within the duration of an endogenous GnRH pulse. Endocrinology 136 138-143.

Won JGS, Oki Y \& Orth DN 1990 Roles of intracellular and extracellular calcium in the kinetic profile of adrenocorticotropin secretion by perifused rat anterior pituitary cells. II. Arginine vasopressin, oxytocin, and angiotensin-II stimulation. Endocrinology $126858-868$.

Wynn PC, Harwood JP, Catt KJ \& Aguilera G 1988 Corticotropinreleasing factor $(\mathrm{CRF})$ induces desensitization of the rat pituitary CRF receptor-adenylate cyclase complex. Endocrinology 122 $351-358$.

Received 8 April 2003

Accepted 16 June 2003

Made available online as an

Accepted Preprint 19 June 2003 